\title{
Effect of passive immunization against LH-RH on gonadotrophin secretion in the ferret
}

\author{
Barbara Gledhill, H. M. Fraser*, and B. T. Donovan \\ Department of Physiology, Institute of Psychiatry, De Crespigny Park, Denmark Hill, \\ London SE5 8AF, and ${ }^{*}$ M.R.C. Reproductive Biology Unit, Centre for Reproductive Biology, \\ 37 Chalmers Street, Edinburgh EH3 9EW, U.K.
}

\begin{abstract}
Summary. Administration of ovine antiserum containing antibodies against synthetic LH-RH to spayed female ferrets caused an immediate fall in plasma LH concentration and by $2 \mathrm{~h}$ after injection circulating levels had declined by $70-80 \%$. A further decline of $50 \%$ was observed on Day 2, but by Day 4 a return to normal levels had begun and control values were regained on Day 6. In contrast, the fall in plasma FSH concentration was delayed, with a significant reduction being first observed on Day 2 and minimal values occurring on Day 4. Control values were regained by Day 7 .

The results accord with the concept that a single hypothalamic releasing factor controls the tonic secretion of both pituitary hormones. However, the slow change in FSH secretion implies that the mechanism for FSH release may be more autonomous than that for LH.
\end{abstract}

\section{Introduction}

Although it is assumed that the control of pituitary gonadotrophin secretion is by a single hypothalamic releasing factor, luteinizing hormone-releasing hormone (LH-RH), the discharge of luteinizing hormone ( $\mathrm{LH})$ and follicle-stimulating hormone (FSH) in the ferret shows marked divergence under several experimental conditions. For example, when lesions were placed in the hypothalamus, a sharp increase in FSH secretion with no rise in LH occurred in some animals but the exact converse in others (Donovan \& ter Haar, 1981), suggesting that separate releasing factors may be produced. Furthermore, daily treatment of ferrets with an LH-RH agonist (HOE 766) consistently induced an elevation in LH secretion but appeared to depress FSH release (Gledhill \& Donovan, 1981), particularly in spayed animals.

One way to investigate the role of LH-RH in the control of LH and FSH is to inhibit its action by injecting antibodies to LH-RH (rat: Koch, Chobsieng, Zor, Fridkin \& Lindner, 1973; ram: Lincoln \& Fraser, 1979; monkey: McCormack, Plant, Hess \& Knobil, 1977) and this approach has now been used for ferrets.

\section{Materials and Methods}

Animals. Eight female ferrets (A. S. Roe, Little Fakenham, Norfolk) were studied, all of which had been ovariectomized at least 6 weeks earlier. Throughout the experiment they were maintained in individual cages under artificial lighting of $8 \mathrm{~h}$ light $(09: 00-17: 00 \mathrm{~h}) / 24 \mathrm{~h}$. They were fed a tinned 'dog convalescent diet' (Petfoods Ltd) once a day with Dog Diet A (Cooper Nutritional Products) and water being available ad libitum. 
Antiserum preparation. The antiserum to LH-RH was obtained from a ewe immunized against LH-RH conjugated to BSA as described by Clarke, Fraser \& McNeilly (1978). Antibody titre was estimated by incubating serial dilutions of the antibody with approximately 20 pg ${ }^{125}$ I-labelled $\mathrm{LH}-\mathrm{RH}$ in a final volume of $300 \mu \mathrm{l}$ at $4^{\circ} \mathrm{C}$. Under these conditions, a 1:40 000 antibody dilution bound $33 \%$ of the added tracer. The in-vivo and in-vitro properties of this antiserum have been described previously (Lincoln \& Fraser, 1979) The control serum was obtained from a ewe immunized against BSA alone. Sufficient antiserum was available for treatment of 4 ferrets in each group only.

Blood collection. The ferrets were catheterized via an external jugular vein under pentobarbitone sodium anaesthesia ( $36 \mathrm{mg} / \mathrm{kg}$, Sagatal: May \& Baker) with the free end of each 'Silastic' polymer catheter (Dow-Corning; $0.64 \mathrm{~mm}$ i.d. $\times 1.19 \mathrm{~mm}$ o.d.; Cat. No. 602-155) passing under the skin to emerge from a stab wound at the nape of the neck.

On the following day, experimental Day 1, 1.2-ml blood samples were collected at 30-min intervals for $7 \mathrm{~h}$ from the conscious but gently restrained animals, with each sample being replaced by an equivalent volume of $0.9 \%(\mathrm{w} / \mathrm{v})$ sodium chloride solution. At $2 \frac{1}{4} \mathrm{~h}$ after the start of sampling, 4 ferrets each received $2 \mathrm{ml}$ antiserum to LH-RH i.v. whilst the remaining 4 females were injected with anti-BSA serum. At the end of sampling the catheters were flushed with heparinized saline and the ferrets returned to the animal room. Further blood samples were taken at 30-min intervals for $3 \mathrm{~h}$ on the afternoons of Days 2, 4, 8 and 15, whilst a single blood sample was taken on all intervening days to Day 20.

Plasmas were separated by centrifugation at $4{ }^{\circ} \mathrm{C}$ and stored at $-20^{\circ} \mathrm{C}$ until hormone assay.

Hormone assay and statistical analysis. The plasma concentrations of LH and FSH were measured by heterologous radioimmunoassays already validated for the ferret (Donovan \& ter Haar, 1977). The LH assays used a rabbit antiserum raised against ovine LH (GDN No. 15) and a highly purified ovine LH as tracer (LER-1056-C2), and the results are expressed in terms of ng NIH-LH-S18/ml. FSH was measured using a rabbit antiserum against ovine FSH (JU 619/II) and a highly purified rat FSH as tracer (NIAMDD-RFSH-I-1), with the values being expressed in terms of ng NIAMDD-FSH-RP $1 / \mathrm{ml}$. The sensitivities of the assays were $0.1 \mathrm{ng} \mathrm{LH} / \mathrm{ml}$ and $30 \mathrm{ng} \mathrm{FSH} / \mathrm{ml}$ and inter- and intra-assay coefficients of variation were $18.6(n=12)$ and $5.8 \%$ respectively for $\mathrm{LH}$ and $9.55(n=17)$ and $2.6 \%$ for $\mathrm{FSH}$.

Statistically significant differences were calculated using the Mann-Whitney U test.

\section{Control ferrets}

\section{Results}

Injection of antiserum to BSA had no effect on the plasma levels of LH or FSH during the experiment. The results for the first 7 experimental days are summarized in Table 1.

\section{Experimental ferrets}

After injection of ferrets with LH-RH antiserum there was a dramatic fall in plasma LH and FSH concentrations but at different times (Text-fig. 1; Table 1). LH values began to fall within $15 \mathrm{~min}$ of the LH-RH antiserum treatment and by $2 \mathrm{~h}$ after injection the level for any individual animal had fallen to $20-30 \%$ of its preinjection mean value. By Day 2 the LH value of each ferret had fallen by a further $50 \%$ and remained stable at this concentration throughout the sampling period with minimal fluctuation. A further decline was seen in 2 ferrets on Day 3 (one of which exhibited the highest antibody titre) but by Day 4 the plasma LH concentration was starting to rise again in all animals and reached control levels by Day 6 , at a time when antibody titres were becoming undetectable. In addition, by Day 4 the individual levels were much less stable and by Day 8 each ferret was showing marked LH fluctuations, possibly indicating a return to episodic release (see Text-fig. 1). 
Table 1. Mean \pm s.e.m. changes in plasma LH, FSH and antibody titre during the first 7 days after treating ferrets with antisera to LH-RH or BSA

\begin{tabular}{|c|c|c|c|c|c|c|c|c|c|}
\hline & & \multirow{2}{*}{$\begin{array}{c}\text { Before } \\
\text { treatment } \dagger\end{array}$} & \multicolumn{7}{|c|}{ After treatment } \\
\hline & & & Day $1 \ddagger$ & Day 2 & Day 3 & Day 4 & Day 5 & Day 6 & Day 7 \\
\hline LH (ng/ml) & $\begin{array}{c}\text { Anti- } \\
\text { BSA } \\
\text { Anti- } \\
\text { LH-RH }\end{array}$ & $\begin{array}{r}3.26 \\
\pm 0.24 \\
3.46 \\
\pm 0.09\end{array}$ & $\begin{array}{l}3.34 \\
\pm 0.16 \\
1.37 \\
\pm 0.18^{* *}\end{array}$ & $\begin{array}{ll} & 3.8 \\
\pm & 0.12 \\
0.49 \\
\pm & 0.03^{*}\end{array}$ & $\begin{array}{c}3.83 \\
\pm 0.11 \\
0.62 \\
\pm 0.13^{*}\end{array}$ & $\begin{array}{c}3.39 \\
\pm 0.06 \\
1.28 \\
\pm 0.05^{*}\end{array}$ & $\begin{array}{ll} & 3.5 \\
\pm & 0.20 \\
1.88 \\
\pm & 0.48^{*}\end{array}$ & $\begin{array}{r}3.95 \\
+0.26 \\
3.09 \\
+0.73\end{array}$ & $\begin{array}{r}4.23 \\
+0.67 \\
3.37 \\
+0.32\end{array}$ \\
\hline $\mathrm{FSH}(\mathrm{ng} / \mathrm{ml})$ & $\begin{array}{c}\text { Anti- } \\
\text { BSA } \\
\text { Anti- } \\
\text { LH-RH }\end{array}$ & $\begin{array}{ll} & 1380 \\
\pm & 120 \\
1130 \\
\pm & 60\end{array}$ & $\begin{aligned} & 1185 \\
\pm & 25 \\
& 1150 \\
\pm & 80\end{aligned}$ & $\begin{aligned} & 1190 \\
\pm & 30 \\
& 535 \\
\pm & 14^{*}\end{aligned}$ & $\begin{aligned} & 1190 \\
\pm & 75 \\
& 340 \\
\pm & 40^{*}\end{aligned}$ & $\begin{aligned} & 1035 \\
\pm & 20 \\
& 310 \\
\pm & 7^{*}\end{aligned}$ & $\begin{aligned} & 1040 \\
\pm & 40 \\
& 480 \\
\pm & 90^{*}\end{aligned}$ & $\begin{array}{c}1095 \\
\pm 50 \\
845 \\
\pm 65^{*}\end{array}$ & $\begin{aligned} & 1120 \\
+ & 40 \\
& 870 \\
\pm & 85\end{aligned}$ \\
\hline $\begin{array}{l}\text { LH-RH } \\
\text { antibody } \\
\text { titre§ }\end{array}$ & $\begin{array}{c}\text { Anti- } \\
\text { LH-RH }\end{array}$ & ND & $400-1200$ & $200-350$ & $100-150$ & $50-100$ & $40-50$ & Trace & ND \\
\hline
\end{tabular}

$\dagger$ Mean of all 20 samples taken before treatment.

$¥$ Mean of all 40 samples taken on Day 1 after treatment.

$\S$ Range of dilutions of plasma that bound 33\% of the labelled LH-RH; ND, not detectable.

Values significantly different from control values: ${ }^{*} P<0.05 ;{ }^{* *} P<0.01$ (Mann-Whitney 'U' test).

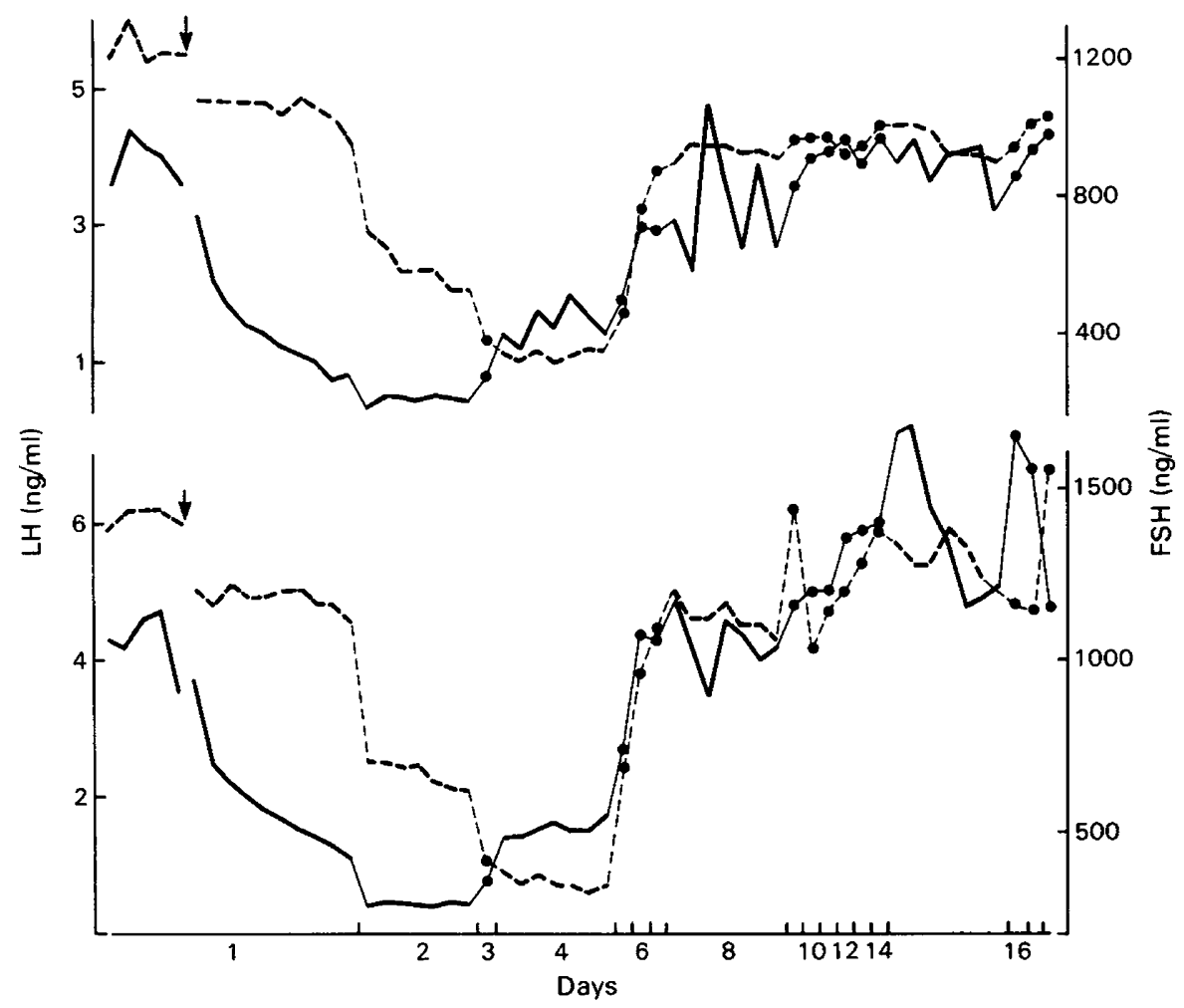

Text-fig. 1. Changes in plasma LH (-) and FSH (--) in all of the samples taken from 2 individual ferrets treated with antiserum to LH-RH (arrows). Thick lines indicate periods of sequential sampling at 30-min intervals whilst single daily samples are represented by dots, with the points connected by thinner lines. 
Concentrations of FSH were not significantly reduced until Day 2 but thereafter there was a significant decline in release and minimal values were reached on Day 4, 2 days after LH and at a time when LH-RH antibody titre in the blood was declining. Values then rose but did not reach control values until Day 7, i.e. 1 day later than for $\mathrm{LH}$.

\section{Discussion}

These results show that passive immunization with antibodies against LH-RH markedly depresses LH and FSH secretion in ovariectomized ferrets. The fall in LH was immediate and by $2 \mathrm{~h}$ after injection circulating levels had declined by $70-80 \%$, a time course reflecting a short half-life of $\mathrm{LH}$ in the circulation and indicating also that its secretion is normally stimulated rapidly by a preceding discharge of LH-RH from the hypothalamus.

In the ram (Lincoln \& Fraser, 1979) and ovariectomized rat (Snabes \& Kelch, 1979) injection of LH-RH antiserum clearly acted by abolishing the episodic release of LH. Although the exact nature of $\mathrm{LH}$ release in the ferret has not been established, the reduction in variation in LH levels when suppressed by the antiserum is in accord with these results in the rat and ram, although the ferret would appear to differ in that basal secretion was also markedly affected.

The slower effect on plasma FSH concentrations indicates that the mechanism of release of FSH from the pituitary gonadotroph cell is more autonomous than for $\mathrm{LH}$, with secretion being possible for a longer period after the LH-RH stimulus has been removed. However, it has been suggested that the inhibitory action of LH-RH antibodies is $<100 \%$ so that a small amount of LH-RH remains biologically active, depending on the titre and affinity of the antibodies (Clarke et al., 1978; Snabes \& Kelch, 1979; Fraser, 1980). This may explain why gonadotrophin secretion does not seem to be completely abolished, but the theory that low levels of LH-RH are thought to favour FSH release in preference to LH (Arimura, Debeljuk, Shiino, Rennels \& Schally, 1973; Fraser, 1980) does not explain the rise in LH secretion in ferrets on Day 4 when FSH was still declining.

The results with ovariectomized ferrets are in general agreement with findings for the ovariectomized rat (Koch et al., 1973), ovariectomized monkey (McCormack et al., 1977) and ram (Lincoln \& Fraser, 1979). As the effectiveness of the LH-RH antibodies declined, particularly marked fluctuations in LH levels were observed in the ferrets (Day 8). An erratic pattern of LH secretion was also observed during the recovery period after injecting antibodies to LH-RH in the Soay ram and it was suggested that this could be the result of increased LH-RH pulsatility following the reduction in testosterone secretion (Lincoln \& Fraser, 1979). Since the ferrets were ovariectomized this explanation does not apply, although a reduction in a short-loop feedback from the pituitary to the hypothalamus may be a factor. An additional possibility may involve changes in pituitary sensitivity to LH-RH. The affinity of ligand binding sites for ligand is known to vary with the ligand concentration, the affinity being highest when the binding sites are virtually completely unoccupied (De Meyts \& Roth, 1975). If this is the case for pituitary LH-RH receptors in the absence of LH-RH, then at the time of maximal LH-RH blockade the pituitary should be extremely sensitive to LH-RH. With the gradual cessation of LH-RH blockade there would be a transition period during which both receptor affinity and pituitary sensitivity revert to normal levels and this is supported by the progressive increase in fluctuation on Days 4 and 8.

In conclusion, the present results tend not to support the idea that separate and distinct releasing factors control FSH and LH secretion in the ferret, because treatment with antibodies to a single releasing factor depressed the secretion of both hormones. It is possible that separate releasing factors for FSH and $\mathrm{LH}$ could share common amino acid sequences to which the antiserum cross-reacted, but resolution of this point must await isolation of the putative FSH-RH in the ferret. 
We thank Dr G. D. Niswender, for the anti-ovine LH antiserum; Dr L. E. Reichert, Jr for purified LH (LER-1056-C2); NIH, U.S.A., for ovine LH (NIH-LH-S18); Dr J. Th. J. Uilenbroek for anti-ovine FSH (JU 619/II); and the NIAMDD for rat FSH (NIAMDDFSH-RP1) and purified rat FSH for iodination. The work was supported by a project grant from the Medical Research Council (G. 977/811) and an equipment grant from the Science Research Council (GR/B. 02248). The excellent technical assistance of Mrs M. Kibble and Miss D. Allwood is much appreciated.

\section{References}

Arimura, A., Debeljuk, L., Shino, M., Rennels, E.G. \& Schally, A.V. (1973) Follicle stimulation by chronic treatment with synthetic LH-releasing hormone in hypophysectomized female rats bearing pituitary grafts. Endocrinology 92, 1507-1514.

Clarke, I.J., Fraser, H.M. \& McNeilly, A.S. (1978) Active immunization of ewes against luteinizing hormone-releasing hormone, and its effects on ovulation and gonadotrophin, prolactin and ovarian steroid secretion. J. Endocr. 78, 38-47.

De Meyts, P. \& Roth, J. (1975) Co-operativity in ligand binding: a new graphic analysis. Biochem. Biophys. Res. Commun. 66, 1118-1125.

Donovan, B.T. \& ter Haar, M.B. (1977) Effects of luteinizing hormone releasing hormone on plasma follicle-stimulating hormone and luteinizing hormone levels in the ferret. J. Endocr. 73, 37-52.

Donovan, B.T. \& ter Haar, M.B. (1981) Acute effects of hypothalamic lesions upon gonadotrophin secretion in the ferret. J. Endocr. 89, 329-336.

Fraser, H.M. (1980) Inhibition of reproductive function by antibodies to luteinizing hormone releasing hormone. In Immunological Aspects of Reproduction and Fertility Control, pp. 143-171. Ed. J. P. Hearn. M.T.P. Press, Lancaster.
Gledhill, B. \& Donovan, B.T. (1981) Repetitive treatment with gonadotrophin releasing factor or a long-acting analogue upon gonadotrophin secretion in the female ferret. J. Endocr. 90, 275-283.

Koch, Y., Chobsieng, P., Zor, U., Fridkin, M. \& Lindner, H.R. (1973) Suppression of gonadotrophin secretion and prevention of ovulation in the rat by antiserum to synthetic gonadotrophin releasing hormone. Biochem. Biophys. Res. Commun. 55, 623-629.

Lincoln, G.A. \& Fraser, H.M. (1979) Blockade of episodic secretion of luteinizing hormone in the ram by the administration of antibodies to luteinizing hormone releasing hormone. Biol. Reprod. 21, 1239-1245.

McCormack, J.T., Plant, T.M., Hess, D.T. \& Knobil, E. (1977) The effect of luteinizing hormone releasing hormone (LHRH) antiserum administration on gonadotrophin secretion in the rhesus monkey. Endocrinology 100, 663-667.

Snabes, M.C. \& Kelch, R.P. (1979) Acute inhibitory effects of antiserum to gonadotrophin-releasing hormone in ovariectomised rats. Evidence for pulsatile secretion of gonadotrophin-releasing hormone. Neuroendocrinology 29, 34-41. 